\title{
Are 'advanced' Japanese language programs sustainable? A look at Australia, New Zealand and Singapore
}

Edition 7, 2021

Associate Professor Carol Hayes, Associate Professor Ikuko Nakane, Nagisa Fukui, Masanori Nagami, Dr Masayoshi Ogino and Dr Emi Otsuji

DOI: 10.37839/MAR2652-550X7.17

Economic, strategic and cultural connections to Japan have never been stronger and more students across the breadth of our education system, primary through to tertiary, continue to be interested in studying Japanese. But what, beyond Demon Slayer and Pokemon, motivates them and how can that knowledge help universities to build effective and engaging language programs?

Japanese is one of the most popular Asian languages taught at tertiary institutions around the world. According to the Survey Report on Japanese-language Education Abroad 2018 (Japan Foundation, 2020), the number of learners outside Japan reached $3,851,774$, the second highest on record, and the number of institutions and teachers was the highest since the Foundation's 1979 survey. Despite the COVID-19 pandemic, enrolment in Japanese language subjects has remained relatively strong, even in 2021. Oceania (the majority from Australia and New Zealand) has the highest number of learners per 100,000 population globally.

However, as the authors of this article, we have become increasingly concerned about the sustainability of advanced Japanese language programs in our 
region-specifically Australia, New Zealand and Singapore.

Language education policies (at the governmental and institutional level) and diminishing investment into language education in the higher education sector have put many Japanese Studies/language programs under strain. Advanced-level subjects generally have lower enrolment numbers than beginner- and intermediate-level subjects, and so are most at risk of being merged, cut back or dropped altogether. According to the US Foreign Services Institute (FSI), Japanese is considered to be one of the 'super-hard languages' that require English native speakers three times as long as French or Italian to attain 'professional working proficiency'. This means that without students' long-term commitment (retention to advanced levels) and well supported, quality education, there can be no sustainable future for Japanese language programs producing highly advanced users of Japanese in those nations.

Against this backdrop, we recently launched the Network for Teaching Advanced Japanese Project (上級日本語Network), supported by a Japan Foundation Sakura Mini Grant 2020. This project provides a platform to collect data through surveys and interviews to better understand the current state of advanced Japanese language programs at university level in Australia, New Zealand and Singapore, and advocate for communities of practice and ongoing support across the sector. This collaboration involves countries that are members of the Commonwealth. Not only are their universities' medium of instruction English, but they also share similar program structures.

The Network for Teaching Advanced Japanese Project approached colleagues from universities in Australia, New Zealand and Singapore in 2020, gathering data on Japanese language programs at 25 institutions in total (Australia 19, New Zealand four, Singapore two). In total, 76 participants responded to the survey and among those respondents, 38 teachers (34 from Australia, two from New Zeland and two from Singapore) participated in online interviews between December 2020 and January 2021. 
Our survey results show that the 'advanced' level was broadly defined by:

- the stage of progression at the institution,

- a proficiency level equivalent to external criteria such as the Japanese Language Proficiency Test or the Common European Framework of Reference for Languages; and

- the demonstration of specific skills through engagement with types of learning activities or resources (eg progression through language textbooks).

What emerged from this is that there is a disparity in what is categorised as constituting the 'advanced level' within different institutional frameworks. Although this may seem merely a comparison with European languages these definitions have significant impact on institutional support for Japanese language.

If institutions only support languages through to what we as teachers define as intermediate then it becomes harder for us to graduate advanced users of Japanese. We found that there are subjects with similar content and resources (for example the same textbook) that are called 'advanced' by some universities and 'intermediate' by others. It is common practice that in a three-year university degree program, students who start as beginners can progress to an 'advanced' level in their final year of study, but in many cases, realistically speaking, this 'advanced' level of study is nevertheless perceived as an 'intermediate' level of language acquisition by tertiary teachers of Japanese. The majority of students from the institutions we surveyed usually have three to four hours of class per week (five to six hours at most) during the semester or term. This gives them an average of around 100 class hours per year, and a total of around 300 over their three-year university degree program. It is clear this is insufficient when compared with 2,200 class hours deemed necessary to reach 'professional working proficiency' for Japanese in the aforementioned FSI estimate (for French and Spanish 600-700 and for German 900 class hours). It should be noted that 'class hours' here may assume that language learning does not occur beyond the classroom. Thus, the need to take account of the fact that tertiary students in Australia, New Zealand and Singapore increasingly 
engage in language learning outside the classroom, for example doing online tasks as part of a blended-learning curriculum, watching Japanese dramas or participating in in-country studies.

Our project also found that there is a tendency for the teaching of Asian languages to be adapted to the framework used in the teaching of European languages. It is for example, common practice for universities to offer Levels 1 - 6 in each language with Levels 5 - 6 defined as 'advanced'. This ignores the fact that students progress differently in different languages. The proficiency level reached by students in Japanese language programs at the official 'advanced' level may well be behind those in European language programs. All three countries involved in this project-Australia, New Zealand and Singapore-operate in an English-speaking context associated with the UK tradition of language education which may explain why European languages (which share the Roman alphabet based writing system with English) tend to be privileged in the institutional frameworks.

There has been enthusiastic promotion of Asian language education (including Japanese) by the Australian and New Zealand governments since late 1990s, and the ongoing social commitment to multiculturalism. Australia, for example, has released several strategic plans such as the National Asian Language Studies in Australian Schools Strategy (NALSAS, 1995-2002) and recommendations on Asian language studies in the Australia in the Asian Century White Paper (2012). The New Zealand government implemented the Asian Language Learning in Schools (ALLiS) program in 2014, and have committed to a total of $\$ 10$ million over five years, aiming to support schools by setting up new Asian language learning programs, or strengthening existing ones. In Singapore, mainly in response to industrial demand, the Ministry of Education established their Foreign Language Centre in 1978 to offer couses of French, German and Japanese for secondary school students (the Centre expanded to Ministry of Education Language Centre to offer language couses in wider age groups). Universities and polytechnics in Singapore also established Japanese language programs from the1980s. 
The development of Asian literacy can be better supported with a less Eurocentric and less English-monolingual mindset. A recent report_May 30, 2021) on the current state of school language programs and assessment in the Australian state of New South Wales suggests European languages such as French are advantaged over Japanese and Arabic, pointing to just such a bias. Further, the dominance of English in the global arena is creating a societal apathy for learning languages other than English. Despite acknowledgement that languages provide a key pathway to fostering 'generalised national multilingualism, social harmony, and economic prosperity' as noted by scholars Shannon Mason and John Hajek, representations of language education in the media can often exacerbate the precarious position of language education in Australia by presenting only superficial, narrow and negative editorial debate.

\section{Challenges to the sustainability of 'advanced' Japanese}

One key element of sustainability is continuity across education sectors. Not everyone starts Japanese as a beginner in tertiary education. Tertiary students who have studied Japanese at school or those who have previous Japanese learning experiences, whether in private or formal settings, start with subjects that are at second or third year progression stage in university Japanese programs. These students can reach a higher level of proficiency by the end of their three year (in Singapore, usually four year) course of university study. Our interviewees often mentioned the importance of long-term cross-sector investment into Japanese language education for sustaining and enhancing proficiency outcomes, including the importance of in-country study in Japan, either on short or longer term exchanges.

There are, however, two significant obstacles to nurturing this important continuity. The first is a structural issue: as university degree programs become increasingly restrictive, students have very little flexibility to add language strands-even in 
elective courses. In Australia, this is compounded by the fact that degrees are increasingly expensive, especially in the humanities and social sciences. Furthermore, although languages sit in the lowest fee category and have been identified as a job-ready skill, students are still turning away from languages to focus on their degree discipline(s). Regular ongoing study is a vital element in language learning and so restricting options for students to enrol in language programs over a number of semesters has a negative impact. The most widely offered option within Japanese language programs at the institutions surveyed is as an 'elective'; so even if university Japanese programs offer attractive subjects to students who have studied Japanese at school, it is not always possible for them to reach an advanced level.

The other obstacle is the status of languages in the secondary sector. As far as Australia is concerned, only 10.3 percent of students in Year 12 (the final year of secondary school) studied languages in 2019 (according to the Australian Curriculum, Assessment, and Reporting Authority). This makes languages the least popular learning area in secondary schools. The Japan Foundation report also points out that the numbers of learners and institutions in the secondary sector in Australia decreased partly because Japanese was replaced by Chinese, and by STEM (science, technology, engineering and mathematics) subjects. In New Zealand this trend is less clear, firstly because Chinese is not so strong in the secondary curriculum and student perception of STEM subjects as 'hard' has meant that students have not turned away from the humanities in the same way. However, only 720 students took Japanese in Year 13 (the final year of secondary school) in 2020, a decrease of 18.8 percent since 2010. Singapore's bilingual education policy put its foreign language education in a quite different context from Australia and New Zealand, particularly as Japanese is mainly offered to high achievers whose mother tongue is Chinese or have learnt Chinese in elementary/primary school. 


\section{The strengths of 'advanced' Japanese teaching}

Our project showed real positives in the student networking, community engagement and global citizenship space. The majority of the teachers in our project provided opportunities for advanced level students to become users of Japanese as plurilingual citizens of the world able to critically evaluate and respond to new problems. At the advanced level, students are exposed to a wide range of authentic materials, and many teachers select contemporary social issues, largely related to Japan, but also issues of global concern for study. While such topics require regular updating of materials and activities, teachers across the network shared deep commitment to fostering their student engagement with contemporary Japan. Many Japanese language programs also provide collaborative activities with Japanese university students and members of the Japanese community where the university is located-thus providing engagement with all types of 'Japanese language users' from a range of localities, not just with native speakers of Japanese. A number of teachers also commented that the online learning environment of COVID-19 has provided an expanded opportunity to invite people from Japan or other locations to their university Japanese classes without having to meet in a single location, thanks to video conferencing tools. We also found that even before the pandemic, there had already been active engagement with blended learning and online communication tools that facilitated learning through authentic communication with Japanese users from different parts of the world.

Teachers who participated in our project observed a tendency for students to study Japanese for integrative motivation, rather than instrumental considerations. In other words, students are genuinely interested in the language and culture, rather than viewing Japanese as a way to secure a desirable career. Teachers repeatedly commented that their students simply 'love Japanese'. This aligns with the Japan Foundation survey results, which places Japanese popular culture as the top 
motivator for learning Japanese amongst university students, followed by an 'interest in Japanese language', and 'study in Japan'. Future employment/work aspirations rank fourth. Some teachers also noted that students may be interested in teaching English in Japan on the Japanese government-supported JET (Japan Exchange and Teaching) as an assistant language teacher because they wish to live in Japan rather than pursue a serious career goal. Students may not be viewing Japanese as something that would lead to a career where Japanese is the main medium of communication. One of the teachers from Singapore also mentioned that multinational corporations and consultancies have become more attractive than Japanese corporations to graduates with Japanese language skills.

A key common thread that emerged from our interviews was that a majority of the teachers took a stance as facilitators of learning for students as 'Japanese users'. Many teachers, regardless of the amount of characters, grammar and vocabulary students have mastered, put their effort into enabling the agency of their students as independent, proactive and critical 'users' of Japanese through activities involving real-life issues and authentic communication in Japanese. Advanced level tertiary students across the three countries in our project are encouraged to engage with materials critically and produce their own work in Japanese to express their own voice in their class activities and assessment tasks. For example in a program in Singapore, students begin with critical reading of news reports, engage in group discussion, and then produce their own reports based on interviews they conduct themselves in Japanese. In another example this time in Australia, students work on topics related to migration, marginalisation and identity drawing on the concept of uchi and soto (literally, inside/outside) in Japanese. One teacher from an Australian university shared topics selected by student research project groups, which included transport hubs in Japan and Australia, cashless society, and sexless couples in Japan. A teacher from a New Zealand university co-organised an online World Café in Japanese with teachers from Korea, Japan and the Philippines. The participating students discussed specific topics in small groups in the structured but relaxed style of World Café, in an attempt to entice students to shift from learners to users. 
It is not surprising to find such approaches to learning, as key graduate attributes in all three countries include critical thinking, becoming independent learners and engaging as proactive social citizens. Critical thinking skills are highly valued by prospective employers, and as a result many universities are introducing WiL (work integrated learning) models. However, in recent years, universities and governments are increasingly prioritising producing 'job-ready' graduates, as seen in the Australian Department of Education, Skills and Employment's recent decision to include languages in the 'job-ready' areas of study. This utilitarian perception of language education has impacted on language education policies in many parts of the world. It presumes instrumental motivation for language studies, despite the fact that students and teachers of Japanese in the higher education context are more inclined towards an integrative orientation to Japanese language learning.

The tertiary Japanese teachers in our project have facilitated advanced level students' development as independent, proactive and critical language users who are able to utilise their unique set of linguistic, cultural and intellectual resources in and outside the classroom. In our region, however, the institutional and governmental stance prioritises (and seems to assume) an instrumental motivation for language learning.

\section{Where are we going with our language education?}

More research is needed to explore what universities and teachers are trying to achieve through tertiary language education. Where are we going with our current practice and what do the current institutional and governmental stances mean to the future of Japanese language education? What sort of linguistic and socio-cultural competencies are required to better prepare students to become more globally literate and effective in working towards societal goals?

Network members noted the need to better understand student motivations for 
learning to an advanced level, and the Japanese Studies Association of Australia has been funded for a further project to draw on this student voice, entitled, Student Motivations: Why continue to the advanced levels of Japanese language learning at university? (Supported by a Japan Foundation Sakura Mini Grant 2021).

Authors: Associate Professor Carol Hayes, Associate Professor Ikuko Nakane, Nagisa Fukui, Masanori Nagami, Dr Masayoshi Ogino and Dr Emi Otsuji.

Image credit: University of Queensland ICTE/Flickr. The image has been cropped. 